\title{
Editorial
}

\section{Changes in cognition following cardiac surgery}

As the mortality rates following cardiac surgery have declined, increasing interest has been focused on morbidity. One area of morbidity that has received growing attention is the impact of cardiac surgery on the brain. The incidence of stroke has now declined and tends to occur in about $1-3 \%$ of cases. ${ }^{1}$ Neuropsychological assessment of patients' cognitive changes following cardiac surgery have been shown to provide a sensitive tool for assessing the impact of, and innovations in, cardiac surgery.

\section{Incidence of neuropsychological deficits following cardiac surgery}

Initially, the purpose of early research into cardiac surgery was to ascertain whether a neuropsychological problem existed after cardiac surgery. This work established that a significant proportion of patients undergoing cardiac surgery exhibit postoperative neuropsychological deficits, which may persist in a number of patients. ${ }^{2}$ The reported incidence, however, varies widely and this inconsistency has been attributed to a number of factors: the number, type, sensitivity, and timing of neuropsychological tests employed. ${ }^{3}$ Most studies assess patients before and at some time after surgery. Assessments in the few days after surgery appear to be contaminated by postoperative discomfort and anaesthetic residue. As a result they tend to yield a higher incidence of deficits. Later assessments, at about eight weeks after surgery, appear to be more stable and are considered to reflect an enduring neuropsychological problem.

The variation in the reported incidence of neuropsychological deficits following cardiac surgery is also likely to be associated with patient related variables such as age and extent of cardiac disease. There is evidence that a general association exists between age and neuropsychological outcome-that is, the older the patient the poorer the outcome. ${ }^{2}$ Centres using differing policies regarding the upper age limit for surgery may well report different neuropsychological outcomes. It has also been suggested that patients are now presenting with more chronic disease, ${ }^{3}$ and there is evidence that individuals with severe cardiac disease may be predisposed to postoperative deficits. ${ }^{4}$

With this changing pattern of patients receiving cardiac surgery it may be expected that more recent studies would report increasing deficit. Two factors work against this expectation. First, individuals recruited into studies may be in better health than those not recruited or those that refuse to take part, ${ }^{3}$ and patients who are more impaired are less likely to attend follow up assessments. ${ }^{5}$ Therefore, the patients most at risk may be less likely to be recruited into these studies. More importantly, however, the increasing improvement of surgical techniques coupled with increased sensitivity of protecting the brain has led to a decline in the number of patients with neuropsychological deficits.

\section{Data analysis}

Much debate has arisen concerning the method of analysing the neuropsychological data to assess the incidence of deficits. Differing techniques can produce a wide variability in reported incidence. This was highlighted by
Mahanna et $a l,{ }^{6}$ who assessed the incidence of decline in 32 cardiac surgery patients. They used five different techniques of analysis, which had previously been used in cardiac surgery research, and found little agreement with incidence varying from $66 \%$ to $15.3 \%$ before discharge, $34 \%$ to $11 \%$ at six weeks postoperatively, and $19.4 \%$ to $3.4 \%$ at six months. At present there is no consensus as to which analysis to use in assessing incidence.

It has been argued that incidence remains an extremely crude method of determining the neuropsychological impact of cardiac surgery. It requires a conventional cut off imposed on a continuous score to indicate a decline, together with a convention as to the number of tests showing such a decline to indicate whether an individual has a neuropsychological deficit. Where studies involve more than one group to compare some aspect of a procedure it is preferable to use both the preoperative and postoperative scores on the tests, and score changes to assess the impact of the intervention. Improvements with repetition in neuropsychological tests are frequently reported despite attempts to remove them. In the context of cardiac surgery and studies that attempt to protect the brain, preservation learning as indicated by an improvement in the neuropsychological test performance may be considered to reflect the protection of the brain during surgery (see Arrowsmith and colleagues ${ }^{7}$ ). The use of score change takes account of both potential preserved learning ability and potential deterioration on the tests providing a sensitive tool for the assessment of interventions in cardiac surgery (see also Grieco and colleagues ${ }^{8}$ ).

\section{What causes deficits?}

Although it is generally accepted that the impact of cardiac surgery on the brain is multifactorial. The most popular explanation for cognitive changes is microemboli delivered to the brain during surgery. These can be either air or particulate (atheromatous matter, fat, platelet aggregates, etc). The measurement of the occurrence of microemboli during cardiac surgery can be achieved with the use of transcranial Doppler where the microemboli produce a characteristic high frequency disturbance "HITS" (high intensity transcranial signals). Transcranial Doppler is now commonly used in cardiac surgery research but, despite some claims to the contrary, researchers are unable to distinguish between gaseous and particulate microemboli.

Neuropathological studies have identified the occurrence of what have been termed small capillary and arteriolar dilatations (SCADs) in the brains of both patients who have died during cardiac surgery and dogs undergoing cardiopulmonary bypass, but not in those who have not been on extracorporeal circulation. ${ }^{9}$ It has been assumed that there is a relation between the microemboli and SCADS, although there are complications with this simple interpretation in that the SCADS appear to resolve over time.

Equipment, anaesthetic and bypass interventions As well as patient characteristics such as age and disease (such as the extent of atheroma) having an impact on neuropsychological outcome, much work has focused on the impact of different techniques and equipment on 
neuropsychological performance. This approach is attractive as these phenomena are potentially open to change. The most direct attempt to deal with the potential deleterious effects of coronary artery bypass grafting (CABG) has been to examine the impact of modifying bypass equipment.

The role of arterial line filters in reducing the impact of microemboli during cardiac surgery has been explored in a number of studies. Padayachee and colleagues ${ }^{10}$ and Pugsley and colleagues ${ }^{11}$ found the introduction of an arterial line filter significantly reduced the number of emboli detected at the middle cerebral artery during CABG. One study found significantly reduced deficits in the filter group $(8 \% v 27 \%)$ eight weeks after surgery. ${ }^{11}$ Comparisons between bubble and membrane oxygenators have shown significant differences in the occurrence of emboli as assessed using retinal fluorescein angiography and some suggestion of reduced neuropsychological deficits in the membrane oxygenator group. ${ }^{12}$

A comparison between pulsatile and non-pulsatile flow failed to find any advantages for either procedure. ${ }^{13}$ Whether these two modes of perfusion are able to lead to perceptible differences in the brain is questionable as Doppler recordings in the middle cerebral artery tend to show non-pulsatility of flow even when pulsatile bypass is used.

The use of hypothermic perfusion during cardiopulmonary bypass has been based on the protective effects of low temperature in limiting the effects of cerebral ischaemia. A number of studies have examined whether hypothermic bypass reduces the impact of cardiac surgery on neuropsychological tests; they have not presented a clear picture. Notably one large study found a significantly higher incidence of neurological problems in normothermia, which was not parallelled in a subset of patients who underwent neuropsychological testing. ${ }^{14}$ The issue of temperature during bypass is more complex than is immediately apparent. For example, what is termed normothermic bypass can involve a range of different procedures such as deliberately re-warming to maintain normothermia, to letting the temperature drift during bypass. Hypothermia occurs at the time most cardiac manipulations are conducted and therefore at the time when emboli are likely to occur. In addition, hyperthermia may occur during re-warming and it is possible that this is the time of most damage to the brain.

Two studies that examined the impact of $\mathrm{pH}$ management both reported advantages for the $\alpha$ stat technique. ${ }^{13}$ Patel and colleagues ${ }^{15}$ reported less disruption to autoregulation in the $\alpha$ stat group, offering some potential explanation for the differences found between $\alpha$ stat and $\mathrm{pH}$ stat regimens.

\section{Pharmacological interventions}

The use of CABG as a model to investigate the efficacy of potential neuroprotective agents is growing in popularity. The reasons for this are that cardiac surgery enables patients to be assessed before the possible insult and again afterwards, a design not possible in stroke studies. Because of the nature of the design and sensitivity of repeating the neuropsychological assessment, the numbers of subjects and the cost of research are significantly less than comparable stroke studies. The use of Doppler to detect microemboli offers an assessment of the degree of embolic load. The mechanisms of ischaemic brain damage are complex leading to a range of possibilities for pharmacological intervention in CABG. Unfortunately, many of the studies reported to date have been underpowered and tended to assess patients too soon after surgery.

Neuroprotection has been used in cases of circulatory arrest where preservation of cognitive function as assessed by neuropsychological tests has been demonstrated. ${ }^{16}$ In
CABG, however, little evidence of neuroprotection has been found. Similar findings have been reported in a study of protacyclin. ${ }^{17}$ Calcium channel blockers and $\mathrm{GM}_{1}$ ganglioside have both been applied in randomised controlled studies but only on small numbers. ${ }^{818}$

One large study ${ }^{7}$ used an NMDA receptor antagonist (remacemide [(+) 2-amino-N-(methyl-1,2-diphenylethil)acetamide] hydrochloride) in a large prospective double blind randomised trial. Patients receiving remacemide $(\mathrm{n}=87)$ had significantly greater preservation of learning on the neuropsychological battery compared to the placebo group $(n=84)$. The increased capacity for learning in the remacemide group may therefore be considered a reflection of the protection accorded the nervous system by this agent during bypass.

\section{Implication of neuropsychological deficits}

As surgery becomes progressively safer and increased techniques for protecting the brain are applied, the incidence of neuropsychological deficits will reduce. The definition of these deficits is conventional and subject to much discussion. What is important is that sensitively analysed they provide a useful tool to examine the impact of new techniques in cardiac surgery on the brain.

S NEWMAN J STYGALL

Unit of Health Psychology,

Department of Psychiatry \& Behavioural Science,

2nd Floor Wolfson Building,

Riding House Street, London W1N 8AA, UK

email:s.newman@ucl.ac.uk

1 McKhann GM, Goldsborough MA, Borowicz LM Jr, et al. Predictors of stroke risk in coronary artery bypass patients. Ann Thorac Surg 1997;63:516-21

2 Newman S. Neuropsychological and psychological changes. In: Smith P, Taylor K, eds. Cardiac surgery and the brain. London: Edward Arnold, 1993: $34-55$

3 Borowicz LM, Goldsborough MA, Selnes OA, et al. Neuropsychologic change after cardiac surgery: a critical review. $\mathcal{F}$ Cardiothorac Vasc Anesthes 1996;10:1326-30

4 O'Brien DJ, Baurer RM, Yarandi H, et al. Patient memory before and after cardiac operations. F Thorac Cardiovasc Surg 1992;104:1116-24.

5 Blumenthal JA, Mahanna EP, Madden DJ, et al. Methodological issues in the assessment of neuropsychologic function after cardiac surgery. Ann Thorac Surg 1995;59:1345-50.

6 Mahanna EP, Blumenthal JA, White WD, et al. Defining neuropsychological dysfunction after coronary artery bypass grafting. Ann Thorac Surg 1996;61:1342-7.

7 Arrowsmith JE, Harrison MJG, Newman SP, et al. Neuroprotection of the brain during cardiopulmonary bypass: a randomised trial of remacemide during coronary artery bypass in 171 patients. Stroke 1998;29:2357-62.

8 Grieco G, d'Hollosy M, Culliford AT, et al. Evaluating neuroprotective agents for clinical anti-ischemic benefit using neurological and neurophysiological changes after cardiac surgery under cardiopulmonary bypass. Stroke 1996;27:858-74

9 Moody DM, Bell MA, Challa VR, et al. Brain microemboli during cardiac surgery or aortography. Ann Neurol 1990;28:477-96.

10 Padayachee TS, Parson S, Gosling TRG, et al. The effect of arterial filtration on reduction of gaseous microemboli in the middle cerebral artery during cardiopulmonary bypass. Ann Thorac Surg 1988;45:647-9.

11 Pugsley WB, Klinger L, Paschalis C, N et al. Does arterial line filtration affect the bypass related cerebral impairment observed in patients undergoing coronary artery surgery? Clin Sci 1988;75(suppl 19):30-1.

12 Smith PL, Blauth C, Newman S, et al. Cerebral microembolism and neuropsychological outcome following coronary artery bypass surgery (CABS) psychological outcome following coronary artery bypass surgery (CABS)
with either a membrane or a bubble oxygenator. In: Willner A, Rodewald $\mathrm{G}$, eds. Impact of cardiac surgery on the quality of life. New York: Plenum

13 Murkin JM, Martzke JS, Buchan AM, et al. A randomized study of the influence of perfusion technique and $\mathrm{pH}$ management strategy in 316 patients undergoing coronary artery bypass surgery. 11 . Neurologic and cognitive outcomes. F Thorac Cardiovasc Surg 1995;110:349-62.

14 Heyer EJ, Adams DC, Delphin E, et al. Cerebral dysfunction after coronary artery bypass grafting done with mild or moderate hypothermia. $\mathcal{F}$ Thorac Cardiovasc Surg 1997;114:270-7.

15 Patel RL, Turtle MR, Chambers DJ, et al. Alpha-stat acid-base regulation during cardiopulmonary bypass improves neuropsychologic outcome in patients undergoing coronary artery bypass grafting. F Thorac Cardiovasc Surg 1996;111:1267-79.

16 Newman S, Pugsley W, Klinger L, et al. The neuropsychological consequences of circulatory arrest with hypothermia - a case report. $\mathcal{F}$ Clin Exp Neuropsychol 1989;11:529-38.

17 Fish KJ, Helms KN, Sarnquist FH, et al. A prospective, randomized study of the effects of prostacylin on neuropsychologic dysfunction after coronary the effects of prostacylin on neuropsychologic dysfunction
artery operation. $\mathcal{F}$ Thorac Cardiovasc Surg 1987;93:609-15.

18 Forsman M, Tubylewicz Olnes B, Semb G, et al. Effects of nimodipine on cerebral blood flow and neuropsychological outcome after cardiac surgery. Br F Anaesth 1990;65:514-20. 